\title{
OUT OF THE CLOSET-FREGE'S BOOTS
}

\author{
by Thomas H. Smith
}

ABSTRACT It is not obvious how one might reconcile Frege's claim that different numbers may not 'belong to the same thing' with his apparent identification of one pair with two boots, even if one grants his view of 'statements of number'. I suggest a way. It requires some revision of the semantic theory that is generally attributed to Frege.

I will, in what follows, attribute two views to Frege that, taken together, look paradoxical. I will then attribute a third view to him, which he seems to put forward as a solution to the paradox. I will then argue that these three views, taken together, look paradoxical too. I then suggest a way of understanding these three views which avoids paradox. But I note that Frege would not have found it congenial.

Here is the first view:

(IDENTITY) One pair of boots may be the same visible and tangible phenomenon as two boots. ${ }^{1}$

There are at least two readings of this claim. According to a weak reading, Frege says that a (visual or tactile) experience of one pair of boots may be indiscriminable from a (visual or tactile) experience of two boots; the pair and the boots may be phenomenologically identical. According to a stronger reading, Frege says that a single pair of boots, (which is a visible and tangible phenomenon), may be straightforwardly identical with two boots. I will take it that this stronger reading is the correct reading of Frege. If I wrongly assume this, it matters little. For Frege ought to be able to reconcile his views with the stronger reading of (IDENTITY) as, thus interpreted, it is true. For while it is false that any two boots are a pair of boots, as two boots must have certain qualitative and historical properties to be a pair, any pair of boots just is two boots. 
If the reader disagrees with me about the truth of (IDENTITY), glossed in terms of the stronger reading, he may try substituting 'one married couple' or 'one coxless pair' for 'one pair of boots', and 'two people' for 'two boots'. Unbiased folk should agree that a married couple or coxless pair just is two people. ${ }^{2}$ To set up the paradox, all I need is some truth of the form ' $n F$ s may be identical with $m G$ s', where $n \neq m$.

The second view that I will attribute to Frege is that nothing is such that distinct cardinal numbers may be truly predicated of it:

(MUTUAL EXCLUSIVITY) [The] examples given earlier give the false impression (Schein) that different numbers may belong to the same thing (dass demselben verschiedene Zahlen zukämen). ${ }^{3}$

So, Frege thinks that one pair of boots is the same as two boots, and that it is false that any thing can be both one and two in number. And that is an apparently paradoxical pair of views: for how can something that is one in number be the same as something that is two in number, if it is false that any thing can be both one and two in number?

Frege seems to think that the paradox is resolved by a third view:

(2nd-LEVEL) ... the content of a statement of number is an assertion about a concept. ${ }^{4}$

I gloss this claim as follows:

Any informative statement as to how many of something there are predicates a concept of a concept. ${ }^{5}$

2. Granted, two married people are not married at all times. But they are to be married at all times prior to their marriage, and were married at all times subsequent to its dissolution, and that suffices to ground identity claims of the form ' $a$ and $b$ are that married couple', just as $a$ 's now being a baker grounds a claim of the form ' $a$ is that baker'. Such claims might be undermined if we could make sense of the suggestion that there are times at which other people are that couple or that baker. But we cannot.

3. Frege op. cit., Sect. 48.

4. Ibid., Sect. 46.

5. It may be that Frege allows for true but uninformative statements of number that predicate concepts of nothing but non-concepts. Hence Frege 1992, p. 81: '... what do we really learn from the sentence "Berlin and Dresden and Munich are three"... Who 
Now, suppose that there is exactly one pair of boots (and no other boots) in Frege's closet. Given (2nd-LEVEL), for anyone to informatively state that there is exactly one pair of boots in Frege's closet, they must predicate a 2 nd-level concept of a 1stlevel concept. The relevant 1st-level concept in this case is, let's assume, _pair of boots in Frege's closet or _pair, for short. To say that there is one such pair is to predicate a 2nd-level concept of that concept, in order to say of it that it is exemplified exactly once. Now, given this view of statements of number, Frege thinks he has a combination of views that is not at all paradoxical. And it's true that he can avoid giving "the false impression that different numbers may belong to the same thing" because the case of his boots will not imply, absurdly, that ${ }_{-} 1$ and $\_2$ 'belong to', or are true of, the same thing, only that ${ }_{-} l$ is true of the concept -pair of boots in Frege's closet (as that concept is exemplified exactly once), while _ 2 is true of the entirely distinct concept _boot in Frege's closet (as that concept is exemplified exactly twice).

But Frege wants to say of those distinct concepts (- pair and _boot), that, even though the number of times they are exemplified differs, they are exemplified by 'one and the same visible and tangible phenomenon', for he says that the pair is the boots. But the claim that the same 'visible and tangible phenomenon' exemplifies _pair exactly once, and_boot exactly twice may seem to be scarcely less absurd than the suggestion that it is both one and two in number. The problem is not that different numbers 'belong to' the same thing; they don't on this view, they belong to distinct things, distinct concepts. But this talk of 'belonging' is cashed out in the following way: the number enumerates the number of times that the concept is exemplified. And on that understanding of what it is for a number to belong to a concept, the appearance of paradox recurs. For we are asked to accept that different numbers, 1 and 2, differentially enumerate the number of times that the concepts _pair and _boot are exemplified, but also that those distinct concepts are exemplified by one and same thing, one and the same "visible

would take the trouble to ask a question in order to get such an answer?' (Note, however, that while the Grundlagen antedates Frege's distinction between Sinn and Bedeutung, this passage post-dates it, and so is open to the objection that we might learn something from 'Berlin and Dresden and Hesperus and Phosphorus are three'.) 
and tangible' phenomenon. But how can one and same thing exemplify _pair once and _boot twice?

Consider the concept _boot. Either an object is a boot or it is not a boot. So either an object exemplifies the concept _boot exactly once, or it does not exemplify it. It is difficult to see what sense can be made of the suggestion that there is a third possibility, namely that an object exemplifies it more than once. It may be granted that we can conceive of someone making, with nails and glue and Sellotape (or perhaps with none of these devices) some kind of 'boot-sculpture', a composite object that is made of boots. But it would not exemplify _boot any number of times; it is not a boot, nor is it several boots, it is, as I said, a composite object, which has certain parts, each of which is a boot, such that each of them exemplifies _boot exactly once. ${ }^{6} \mathrm{We}$ cannot, I submit, make sense of the suggestion that some object exemplifies_boot exactly twice. Yet Frege seems to think a pair of boots is identical with some such object.

Using ' $P$ ' for '_pair', and ' $B$ ' for '_boot', we might try to formalize Frege's apparently paradoxical combination of views thus:

$$
\left(\exists_{1} x\right)\left(\exists_{2} y\right)(P x \& B y \& x=y) .
$$

But Frege cannot think that there is exactly one object $x$ such that $x$ is a pair, exactly two $y$ s such that $y$ is a boot, and that $x$ is identical to $y$. For how should we understand the claim that $x$ is identical to $y$, when there are two $y$ s? This simply makes no sense. We can understand the suggestion that $x$ is identical with something that is made of two $y \mathrm{~s}$; but to make any such claim about the pair of boots in Frege's closet would be to assimilate the case of the pair with the case of the boot-sculpture, which is quite wrong: the pair is not something that is made of two boots, it is two boots.

6. Similarly, a copse is a composite object, which has certain parts, each of which is a tree, such that each of them exemplifies _tree exactly once, not least because, as Wiggins (2001, p. 52) notes, it 'tolerates replacement' of those parts. That indicates, to Wiggins and to me, that we should disavow a strong reading of a Grundlagen claim that parallels (IDENTITY), viz., "While looking at one and the same external phenomenon, I can say with equal truth both "It is a copse" and "It is five trees" (1996, Sect. 46). The strong reading of (IDENTITY) cannot be denied on analogous grounds, as a pair of boots, like a married or coxless pair, does not 'tolerate replacement' of either of the objects that it is a pair of. 
Perhaps this more perspicuously represents Frege's overall view:

$$
\left(\exists_{1} x\right)\left(\exists_{1} y\right)\left({ }_{1} P x \&{ }_{2} B y \& x=y\right) .
$$

The formula may be read as making the following claim: there is exactly one object $x$ such that $x$ is one pair, exactly one $y$ such that $y$ is two boots, and $x$ is identical to $y$. ' $x=y$ ' now makes sense. But does the rest? It is hard to see how exactly one $y$ may be exactly two boots. Someone may darkly say that exactly one $y$ may be 'articulated', by the concept _boot, into two boots, but what is meant by 'articulation' here? The metaphors that tend to be reached for fall, broadly, into two families. Either some notion of division is appealed to - the concept _boot 'slices' or 'cuts' $y$ (as a 'cookie-cutter' cuts) into two boots - or the idea of organization is — the concept _boot 'sorts', 'gathers' or 'collects' $y$ into two boots. Let us consider the former metaphor. The thought appears to be that the concept _pair and the concept _boot provide us with 'instructions' for (notionally or physically) dividing the same object in different ways. But this trivializes Frege's identity claim, for the concept _boot and the concept _boot-sculpture also provide us with 'instructions' for (notionally or physically) dividing the same boot-sculpture in different ways, but we would not say that a boot-sculpture is some boots, as a pair of boots is some boots; rather, it is made of boots. Moreover, if one's notion of division permits of remainder then any two concepts, if they are exemplified, provide us with 'instructions' for (notionally or physically) dividing the same object, namely the world, in different ways, and Frege's identification of the boots and the pair is rendered even more trivial.

By contrast, the second metaphor, that of organization, renders the thought that _pair and _boot are exemplified by distinct 'articulations' of the very same object obscure rather than trivial, hence Davidson:

We cannot attach a clear meaning to the notion of organizing a single object ... Someone who sets out to organize a closet arranges the things in it. If you are told not to organize the shoes and shirts, but the closet itself, you would be bewildered. 
How would you organize the Pacific Ocean? Straighten its shores perhaps, or relocate its islands, or destroy its fish. ${ }^{7}$

Davidson's text, however, contains the clue to our puzzle, for he suggests that, while one cannot sort or organize a closet, one can sort or organize the shoes (or boots) that it contains; one might for example sort them into pairs. Further down the page, he puts it in a nutshell:

The notion of organization applies only to pluralities. ${ }^{8}$

That suggests the following line of thought: it makes no sense to say of an object that it exemplifies one monadic concept ${ }_{-} F$ exactly once and some other monadic concept $G$ several times, such that $F$ and _ $G$ 'sort' it into objects of different number. ${ }^{9}$ If it is an object - an element of the domain - then if it exemplifies a monadic concept, it does so exactly once. It cannot be conceptually 'organized' into several objects. But it makes perfect sense to say of several objects - of a plurality of objects - like the boots in Frege's closet, if not the closet itself, that they can, between them, exemplify one monadic concept exactly once and some other monadic concept several times. For a plurality of boots can be 'sorted' or 'organized' by a monadic concept into 'sub-pluralities' as well as into objects; boots can be sorted into pairs, as well as (trivially) into boots. Hence, some boots may, between them, exemplify _pair some number of times and_boot some other number of times, for while two boots are needed to jointly 'fill' the 'gap' in _pair, only one boot is needed to 'fill' the 'gap' in _boot. As a consequence, _pair can 'sort' a plurality $p$ into the one or more sub-pluralities that exemplify it and that are among $p$, while _boot can 'sort' the very same plurality $p$ into the one or more objects that exemplify it and that are each one of $p$. Hence, distinct monadic concepts like _boot and _pair, can differentially 'sort' the same visible and tangible plurality of objects into objects, and into pluralities thereof, such that for any such 'sorting' of a plurality into objects

7. Davidson 1990, Essay 13, p. 192.

8. Ibid.

9. By a 'monadic concept', I mean a concept that is predicated by a predicate that may combine with a single occurrence of a term to form a well-formed sentence. 
or sub-pluralities, one may map those objects or sub-pluralities severally onto cardinal numbers $1,2,3$, etc., and thereby say how many of them there are. And that is what we do when we count boots and pairs.

If that is along the right lines, the paradox can be dispelled. For while the concepts _pair of boots in Frege's closet and _boot in Frege's closet are not exemplified by one and the same 'visible and tangible' object, they are exemplified by one and the same plurality of 'visible and tangible' objects. And while it would give a 'false impression' to say that 'different numbers may belong to the same thing', it would not give a false impression to say that, by differentially enumerating the distinct concepts _pair and _boot, which are exemplified (once and twice respectively) by the same things, different numbers belong to the same things. Given that Frege's closet is an element of the domain, any concept that it exemplifies, which nothing else exemplifies, is exemplified exactly once. But as Frege's pair of boots are not an element of the domain, but some elements of it, they may exemplify _pair of boots in Frege's closet and _boot in Frege's closet, such that nothing else exemplifies them, but exemplify the former concept exactly once, and the latter exactly twice.

The key presupposition here is that some monadic concepts, like _pair, can be exemplified, although no object exemplifies them; rather, some objects do. In other words, we should deny the following claim:

(SINGULAR EXEMPLIFICATION) For any monadic concept ${ }_{-} F$, for every exemplification of ${ }_{-} F$, there is exactly one object that exemplifies $\_F$.

Given this denial, the standard interpretation of second-level predications can be changed, thus:

$(\exists x) F x=_{\mathrm{df}-} F$ is exemplified at least once

$\neq_{\mathrm{df}}$ there is at least one object that is $F$.

$\left(\exists_{1} x\right) F x=_{\mathrm{df}-} F$ is exemplified exactly once

$\neq_{\mathrm{df}}$ there is exactly one object that is $F$.

$\left(\exists_{2} x\right) F x={ }_{\mathrm{df}-} F$ is exemplified exactly twice

$\neq_{\text {df }}$ there are exactly two objects each of which is $F$. 
The function of the bound variable is, in each case, to keep track of the identities of the thing or things that exemplify ${ }_{-} F$, without prejudice as to their number. If we keep these interpretations in mind, then we can accurately represent a view that reconciles (IDENTITY), (MUTUAL EXCLUSIVITY) and (2nd-LEVEL) by the formula that initially puzzled us.

$$
\left(\exists_{1} x\right)\left(\exists_{2} y\right)(P x \& B y \& x=y)
$$

For we may gloss this in roughly the following terms:

_pair is exemplified exactly once by the very same thing or things as those that exemplify_boot exactly twice.

Frege would not have found this suggestion congenial, for at least two (related) reasons. First, he appears to assume (SINGULAR EXEMPLIFICATION), as a consequence of a more general assumption that the number of 'gaps' in a concept is equal to the number of entities that 'fill' those 'gaps' on any occasion of its exemplification. Secondly, on the resolution of the paradox that I have suggested, the relation of 'identity' that a pair of boots bears to boots is not the relation that is predicated by the sign of equality, as standardly interpreted, for that expression takes only singular terms or variables as arguments; that is, expressions that pick out, or stand for, on any occasion of use, an object, rather than a plurality of objects. But if the pair of boots in Frege's closet and the boots in Frege's closet are, not the very same thing, but the very same things, then, it would seem, 'the pair of boots in Frege's closet' and 'the boots in Frege's closet' are not singular terms, but plural terms, i.e., expressions that pick out, on any occasion of use, several objects, and there must be an identity predicate that such plural terms may flank; yet Frege did not countenance any such terms or any such predicate. ${ }^{10}$

10. I do not here mean to deny that there may be ways of 'regimenting' plural terms and plural identity predications using 2nd-level predicates, just as there are familiar ways of 'regimenting' singular terms and singular identity predications using 2nd-level predicates. But (IDENTITY), thus regimented, will, as far as I can see, still feature a predicate, namely '-pair', that is jointly satisfied by several objects. Hence, the key amendment to Fregean semantics offered in the text is the denial of (SINGULAR EXEMPLIFICIATION). 
The suggestion that a Fregean semantics would do well to admit plural terms is not a novel one. Some of those who make it dispute (2nd-LEVEL), and try to argue that Frege's case for it is undermined by the countenance of plural terms. ${ }^{11} \mathrm{I}$ am not of their number. I favour (but have not argued for) the orthodox opinion that (2nd-LEVEL) is, in Wiggins's fine phrase, 'true and unshakeable'. ${ }^{12}$ I have tried to agitate orthodoxy merely by noting that Frege is committed to (IDENTITY), (MUTUAL EXCLUSIVITY) and (2nd-LEVEL), and that, if one is to avoid fudging the metaphysical distinction between the relation of identity that pairs bear to boots, and the relation of composition that boot-sculptures bear to boots, one will struggle to make sense of this combination of commitments unless one draws upon the resources of a pluralist semantics, in particular by denying (SINGULAR EXEMPLIFICATION). ${ }^{13}$

\author{
Fitzwilliam College \\ Cambridge CB3 ODG \\ $U K$ \\ ths24@cam.ac.uk
}

\title{
REFERENCES
}

Bell, D. 1991: Husserl. London: Routledge.

Davidson, D. 1990: Inquiries into Truth and Interpretation. Oxford: Clarendon Press.

Frege, G. 1992: 'Illustrative Extracts from Frege's review of Husserl's Philosophie der Arithmetik'. In P. T. Geach and M. Black (eds), Translations from the Philosophical Writings of Gottlob Frege. Oxford: Blackwell.

Frege, G. 1996: The Foundations of Arithmetic: A Logico-Mathematical Enquiry into the Concept of Number. Translated by J. L. Austin. Evanston, IL: Northwestern University Press.

Simons, P. 1982: 'Three Essays in Formal Ontology'. In B. Smith (ed.), Parts and Moments: Studies in Logic and Formal Ontology. Munich: Philosophia.

Wiggins, D. 2001: Sameness and Substance Renewed. Cambridge: Cambridge University Press.

Yi, B.-U. 1999: 'Is Two a Property?'. Journal of Philosophy, 96, pp. 163-90.

11. See Simons 1982, Essays II and III; Bell 1991, Ch. 1; and Yi 1999.

12. Wiggins, loc. cit.

13. I have had useful conversations about earlier versions of this paper with Robin Cameron, Ben Caplan, Richard Evans, Mark Eli Kalderon, Fraser MacBride, Mike Martin, Ray Monk, Alex Oliver, Ian Rumfitt and Paul Snowdon. Thanks are also due to audiences in London, Manchester and Southampton. I am grateful to the AHRB and the Wingate foundation for financial assistance received during the writing of this paper. 